\title{
Sequence recompletion: A practice for managing lapses in conversation
}

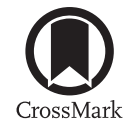

\author{
Elliott M. Hoey* \\ Max Planck Institute for Psycholinguistics, The Netherlands
}

Received 25 August 2016; received in revised form 8 December 2016; accepted 9 December 2016

\begin{abstract}
Conversational interaction occasionally lapses as topics become exhausted or as participants are left with no obvious thing to talk about next. In this article I look at episodes of ordinary conversation to examine how participants resolve issues of speakership and sequentiality in lapse environments. In particular, I examine one recurrent phenomenon-sequence recompletion-whereby participants bring to completion a sequence of talk that was already treated as complete. Using conversation analysis, I describe four methods for sequence recompletion: turn-exiting, action redoings, delayed replies, and post-sequence transitions. With this practice, participants use verbal and vocal resources to locally manage their participation framework when ending one course of action and potentially starting up a new one.
\end{abstract}

(C) 2017 Elsevier B.V. All rights reserved.

Keywords: Conversation analysis; Lapses; Sequence organization; Turn-taking; Silence

\section{Introduction}

It is a regular occurrence in conversational interaction for silence to emerge at the end of a sequence of talk, and then for someone to end that silence with some utterance that neither forwards the topic nor implicates some next action. Take for example Extract 1, which begins with Hannah informing Molly about their university's interlibrary loan program (a more technical analysis is given in Section 3). Transcripts follow Jefferson (2004) for verbal/vocal conduct and Mondada (2014) for bodily conduct.

(1) RCE25_1

01 HAN: you're only allowed a certain number of inter: (.)

02 library loans though aren't you.

((some lines omitted))

03 HAN: I think it's something like thi:rty.

04 MOL: [oh okay.]

05 HAN : [but-(.)] just s- (.) so you know.

\footnotetext{
* Correspondence to: PO Box 310, 6500 AH Nijmegen, The Netherlands.

E-mail address: elliott.hoey@mpi.nl.
} 


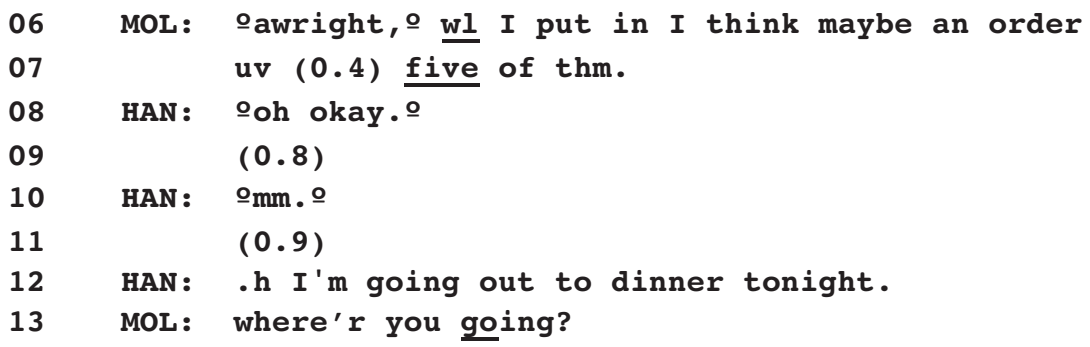

In this sequence of talk, Hannah informs Molly that they're allowed to borrow up to thirty books (lines 1-3). Molly receipts this information (line 6) and reveals that she only ordered five, which is safely below the maximum. Hannah, in turn, receipts this information (line 8), which brings the sequence to a place where it could stop and something else could start up. The range of things that could happen next include topic continuation, resumption of some prior matter, initiation of new interactional business, and so on. None of these options are selected, however. Instead, there is silence (line 9). This silence is a lapse; it results from both participants forgoing the chance to speak. In this lapse environment, Hannah produces a quiet $\mathrm{mm}$ (arrowed). With this token, she merely registers what transpired in the prior sequence, implicates no specific next action, and brings the sequence to completion once more. That is, she recompletes the sequence. In this paper I expand on observations made in Hoey (2015) by examining this practice-sequence recompletion-through which participants reoccasion the relevance of sequence closure in a place where a sequence was already complete. I will try to show that participants use things like $\mathrm{mm}$ in lapse environments as a way to manage issues related to turn-taking, sequence organization, and participation.

\section{Sequence completion and lapses}

Sequences are vehicles through which participants collaboratively bring off courses of action in interaction. A generic concern for participants is locating where sequences might end (see Schegloff and Sacks, 1973). According to Schegloff (2007), the definitive mark of sequence completion is the initiation of another sequence, as this reveals a speaker's understanding of the prior sequence as finished. However, participants do not always know in advance whether someone will initiate a new sequence. They can only parse the unfolding interaction for indications of possible completion (see Schegloff, 2006), whereupon they may justifiably treat the sequence as complete by, for instance, initiating another one. The general question addressed in this paper is how participants produce and recognize possible sequence completion.

How participants arrive at possible sequence completion is bound up with how a sequence begins. A sequenceinitiating action may straightforwardly indicate what it would take to adequately address it. For example, a sequence initiated with a request comes to possible completion once that request is either granted or denied (Schegloff, 1990). And a sequence that begins with other-initiated repair may be complete upon the provision of a repair solution (Schegloff, 2007). These sequences form adjacency pairs, where an initiating action makes conditionally relevant a type-matched responsive action from another participant (Schegloff, 1968, 2007; Schegloff and Sacks, 1973). Many sequences, then, may be treated as finished with the production of a type-matched response to the initiating action.

This picture is complicated by the fact that possible sequence completion is inherently provisional, as participants may always expand the sequence (Schegloff, 2007). Even if some turn constitutes an adequate sequence ending, participants can always go on with that course of action. Sequence expansion may be minimal, as with sequence-closing thirds (SCT) like oh, okay, or assessments, through which participants display preparedness for ending the current sequence and produce something that could embody its completion. Conversely, sequence expansion may project further talk, as with repair initiation or topicalization of something from the prior sequence (Schegloff, 2007).

The abiding possibility of expansion permits sequences to grow rather long and complex such that recognizing completion is not so straightforward. Sequences that are organized by topic talk, for instance, systematically obscure what it would take to count as adequate completion. This is because they characteristically progress in a stepwise fashion, with the boundaries of topics/sequences shading into one another, and participants shifting between speakership and recipiency (Jefferson, 1981, 1983a; Button and Casey, 1988; Schegloff, 1990; Sacks, 1992). For closing such extended sequences, participants can use sequence-closing sequences. This typically involves a proposal to end the sequencefor example, through an upshot, summary assessment, or something that demonstrates a grasp of what just transpiredfollowed by alignment in movement to closure by coparticipants (Schegloff, 2007: 168; see also Curl et al., 2006; Schegloff, 2009; Park, 2010). Participants also use certain multimodal practices to recognize sequence completion, like attenuating prosody from one turn to the next (Goldberg, 1978), gaze withdrawal (Rossano, 2012), and retraction of or shifts in bodily disposition (Goodwin, 1981; Schegloff, 1998; Mondada, 2015).

However participants arrive at possible sequence completion, the basic range of operations available at that point are a) stay with the same course of action (expansion), b) go on to something else (sequence initiation), or $\mathrm{c}$ ) neither of these 
(silence). If this last option is chosen by all participants, then a lapse emerges (Sacks et al., 1974; Author Year). There are many ways that participants arrive at places where talk may lapse, and many ways that participants orient to them once they emerge (Sacks et al., 1974). Lapses may occur during "states of talk" (Goffman, 1967: 34), where participants have arranged themselves to engage in turn-by-turn talk, and for which talking is the central remit of their gathering. For such settings, lapses emerge when all participants refrain from sequence expansion and sequence initiation. The silence results from participants doing nothing where something could have been done. These lapses can pose problems in turntaking (who speaks next?) and sequence organization (what's relevant next?). The development of a lapse at possible sequence completion indicates both the absence of a next speaker and the absence of something to talk about next. Without a next speaker and without an apparent next thing to talk about, what can speakers do? I suggest that these circumstances provide for sequence recompletion. Through sequence recompletion, speakers exploit the pliability of sequence endings to reoccasion the relevance of sequence closure and display that they will not speak immediately next.

Sequence recompletion resembles practices described elsewhere. Notably, Jefferson (1981, 1983a) described how recipients use acknowledgment tokens and assessments in sequentially weak, topically neutral, and disengaged ways so as to shift or close down topics/sequences. Specifically, when participants in sequence-final environments twice pass up the chance to initiate a sequence, conversations enter a state of "topic attrition" (1983a: 21). Similar observations about acknowledgment tokens and assessments have been made for Australian English (Gardner, 2001), Finnish (Sorjonen, 1996, 2001), Korean (Hayashi and Yoon, 2009), and Japanese (Hayashi and Yoon, 2009; Iwasaki, 1997; Tanaka, 2010). This article builds on these studies by describing how English-speaking participants use acknowledgment tokens, assessments, and other closure-implicative objects in managing the practical issues related to lapses in conversational interaction.

This study uses conversation analysis (e.g., Sidnell and Stivers, 2013) to describe sequence recompletion, a practice whereby participants reoccasion the relevance of sequence completion after the sequence was already treated as complete (i.e., after a lapse). With this practice, participants in lapse environments provide a minimal 'something' where 'something' is due, and no more than that. The practice is analyzed through individual cases and through the collection as a whole. I begin with a detailed analyses of an initial specimen to present the general features of the practice and specify the procedure used in building a collection. Then, I discuss some aspects of the entire collection. In the bulk of the paper, I describe four methods used for sequence recompletion (turn-exiting, action redoings, delayed replies, and post-sequence transitions) and analyze a deviant case. With this study of sequence recompletion, I aim to show one recurrent way that participants in a lapse manage the interstice between one course of action and a next one.

\section{The practice}

\subsection{An initial specimen}

Many features of sequence recompletion are exhibited in Extract 1, presented below as Extract 2 with visible conduct transcribed. Possible sequence completion is marked with an arrow $\rightarrow$, and sequence recompletion with a double arrow $\rightarrow \rightarrow$.

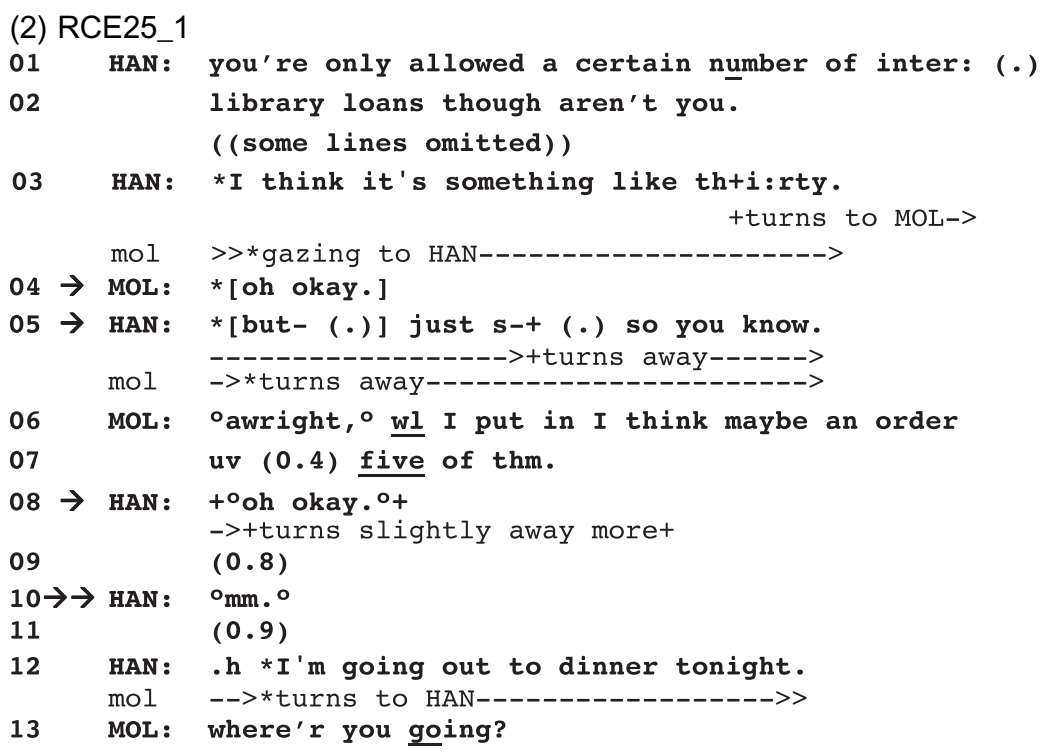


Just before this extract, Molly reported that she used their university's interlibrary loan system to get some books. This topic occasions a warning from Hannah, who cautions Molly of a limit on the number of books she can get through interlibrary loan (lines 1-3). Molly receipts this with the SCT oh okay (Schegloff, 2007) and turns away from Hannah (Rossano, 2012), thereby treating the sequence as nearing completion. In overlap (line 5), Hannah also orients to sequence closure by turning away from Molly while producing an upshot just so you know (see Drew and Holt, 1998), which serves to end her warning to Molly. And so this sequence has arrived at possible completion, as each participant has disengaged both verbally and bodily (Goodwin, 1981). The sequence does not end here, however. Molly expands it by acknowledging Hannah's upshot and dispelling her concern about surpassing the maximum number of books (line 67). Hannah quietly receipts this with the SCT oh okay while turning away even more (line 8), bringing their sequence to possible completion again.

At this juncture, either participant could self-select and, for instance, keep talking about interlibrary loans or some other matter. Alternatively, they could remain quiet-which is indeed what happens, resulting in a 0.8-s lapse (line 9). This lapse represents each participants' choice to do nothing in the place where something could be done, and as such amounts to sequence closure (Schegloff, 2007).

Hannah ends the lapse with sequence recompletion. She produces a quiet $\mathrm{mm}$ (line 10). This decision to speak comes after her initial decision to not speak. However, with this decision to speak she retains the stance embodied in her first choice. That is, she shows with $\mathrm{mm}$ that she will not speak. It lets her display that she will not produce something that would implicate a next turn (Jefferson, 1983a; Schegloff, 1982). Mm is a designedly weak acknowledgment token that selects no next speaker and projects no further talk (Gardner, 2001). For this particular token, several features cumulatively operate to allow her to recognizably display that she will not produce more immediate talk. She produces the $\mathrm{mm}$ quietly, with a falling intonation contour, in closed-lip formation (Raymond, 2013, p. 188), while turned away from her coparticipant (Goodwin, 1981), all of which project no further talk.

Hannah thus twice indicates that she won't produce more talk: first when refraining from self-selection at possible sequence completion, and then again with $\mathrm{mm}$ after the lapse. By passing on the chance to speak, Hannah renews the opportunity for Molly to self-select. There is a corollary here with telephone openings (Schegloff, 1986). After exchanging how-are-yous, the caller typically gets the chance to launch the interactional business. The caller, however, may pass on this opportunity, which provides the called party a chance to do something with that slot. Similarly, with sequence recompletion participants pass on the opportunity to do something that would project more talk, thereby implicitly nominating some other party as next speaker.

The production of something in this space reveals an orientation to the continued relevance of talk here. Hannah's $\mathrm{mm}$ is a minimal 'something' where 'something' is due. This points to an understanding that 'talking' is their current activity, even though no talking is going on. It lets her show nominal engagement in their activity as that activity, while at the same time doing no more than that (Hoey, 2015). We also see that her $\mathrm{mm}$ is followed by silence (line 11). This silence (a second lapse) confirms the analysis above that she designed her $\mathrm{mm}$ as complete, rather than the beginning of a turn. This is also evidenced by the fact that her $m m$ doesn't attract Molly's gaze, indicating that the $m m$ is not hearable as turn-initial.

Hannah then takes an audible inbreath (line 12). Once she does so, Molly swiftly turns to her, thereby orienting to it as turn-initial. And indeed, Hannah's inbreath is immediately followed by a talk that ends the lapse (line 12). So while a quiet $\mathrm{mm}$ doesn't attract Molly's gaze, an inbreath does. This shows that it's hearable as an incipient turn-beginning (Jefferson, 1981; Lerner and Linton, 2004; Schegloff, 1996), and suggests that participants in lapse environments are sensitively attuned to the issue of who speaks next.

\subsection{General features}

Extract 2 serves an exemplary instance of sequence recompletion, and lets us describe the general features of the practice, which is schematized as follows:

\section{A: POSSIBLE SEQUENCE COMPLETION \\ (LAPSE)}

A/B: SEQUENCE RECOMPLETION

First, some participant produces something brings the sequence to possible completion (e.g., a sequence closing third). These places corresponded with the production type-matched responses that complete adjacency pairs (Schegloff and Sacks, 1973), sequence-closing thirds that round off a sequence, or sequence-closing sequences that wrap up extended sequences (Schegloff, 2007). Possible completion was also identifiable via prosodic (Goldberg, 1978) and bodily practices for sequence closure (Rossano, 2012; Mondada, 2015). 
Second, a lapse emerges. Silence was considered a lapse under two conditions. First, no speaker-selection technique (e.g., Sacks et al., 1974; Lerner, 2003; Mondada, 2007) was observed in the prior turn or in the 500-ms of silence thereafter. And second, the participants remain observably committed to the interaction, as displayed through their bodily configurations (Goffman, 1963; Schegloff, 1998). 500-ms was used not because all lapses necessarily occur at this threshold, but because it represents an estimated lower limit for exercising the options in the turn-taking ruleset, as suggested by the timing of 'same speaker continues' in Dutch (ten Bosch et al., 2005) and other-initiated repair in English (Kendrick, 2015). And while impressionistic measurements of timing have been shown to be analytically useful (e.g., Couper-Kuhlen, 1993), instrumental measurements are used here for quantitative analyses (see section 4.1).

And third, some participant (either the same one as before or someone else) produces something that could serve as another sequence ending, recompleting what was already treated as adequately complete. Any verbal/vocal form was counted as a sequence recompleter if it was analyzably tied to the prior sequence (see section 4.2), but did not implicate a response or otherwise forward the prior sequence.

\section{The collection}

The collection is 90 cases of sequence recompletion. These were identified in recordings of casual conversations in American and British English between friends, coworkers, and intimates in homes, at university, and over the phone. Informed consent was given for all recordings, a full list of which appears in the Appendix. Most cases (83/90) come from a sample of 500 lapses that were systematically identified in ten video recordings (see Appendix). This sample of 500 lapses was created by taking the first 50 lapses from these ten recordings. The first 50 were selected because I did not expect them to behave differently from the last 50 , the middle 50 , or a randomly selected 50 lapses in a given recording. These 83 cases are used in the quantitative analyses and descriptive statistics in the next section. The remaining cases $(7 / 90)$ were identified in an additional sample of recordings for the purpose of supplementing the 83 cases with clearer instances of the practice. Because these seven cases were selected in a more opportunistic way, they do not figure into the quantitative analyses below.

\subsection{Lapse duration}

Silence may be a constitutive part of a practice (e.g., Kendrick, 2015; Kendrick and Torreira, 2015). For sequence recompletion, a natural question is how long a lapse goes on before participants end it. Quantitative analysis of lapse duration shows that most cases of sequence recompletion occur after about one second of silence $(M=1.67 \mathrm{~s}$, $M d n=1.12 \mathrm{~s}, S D=1.46, n=60) .{ }^{1}$ This suggests that participants wait about a second before recompleting the sequence (cf. Wilson and Zimmerman, 1986). This in itself is an interesting finding as it comes very close to Jefferson's (1983b) proposal of a one second standard maximum of silence for conversation.

We can compare lapse duration before sequence recompletion $(n=60)$ to lapse duration before anything other than sequence recompletion (e.g., sequence expansion or initiation), of which there are 440 cases in the sample of 500 lapses. When we look at lapse duration before actions other than sequence recompletion, we see a similar median duration of just over a second $(M=1.84, M d n=1.24, S D=1.84, n=440)$. This similarity is visualized in Fig. 1 .

We tested in $\mathrm{R}$ ( $\mathrm{R}$ Core Team, 2013) whether the use of sequence recompletion affects the duration of the lapse. We used a general linear mixed effects model with lapse duration as the outcome variable, lapse behavior as the predictor (usage of sequence recompletion [ $n=60]$ vs. non-usage of sequence recompletion [ $n=440]$ ), and the recording and number of participants as random effects. The usage of sequence recompletion did not significantly affect lapse duration; $\beta=-.32, z=-1.24, p=.22$. Most participants evidently wait about $1 \mathrm{~s}$ before ending a lapse, whether through sequence recompletion or something else. While suggestive, these results are limited by the sample, which was not fully randomized, and await confirmation by further testing using a more controlled sample.

These findings support Jefferson's (1983b) proposal that conversationalists tolerate one second of silence before speaking. They also provide evidence for viewing sequence recompletion as an alternative to things like sequence initiation and expansion in a lapse. One second is apparently the temporal neighborhood for things like sequence initiation, expansion, and recompletion, indicating a kind of positional equivalence between these actions. The time it takes for participants to realize that no one is speaking, locate something to say, and then say it, is similar for both sequence recompleting moves and non-sequence recompleting moves. And so while silence is a constitutive part of the

\footnotetext{
${ }^{1} n=60$ here instead of 83 because I only measured silence occuring before a first instance of sequence recompletion. That is, $23 / 83$ cases were non-initial instances. This is seen in Extract 8, which shows a first sequence recompleter in line 10 and a subsequent one in line 14 . The silence before the first recompleter was used (i.e., part of the 60/83); the silence before the subsequent one was not used (i.e., part of the 23/83).
} 

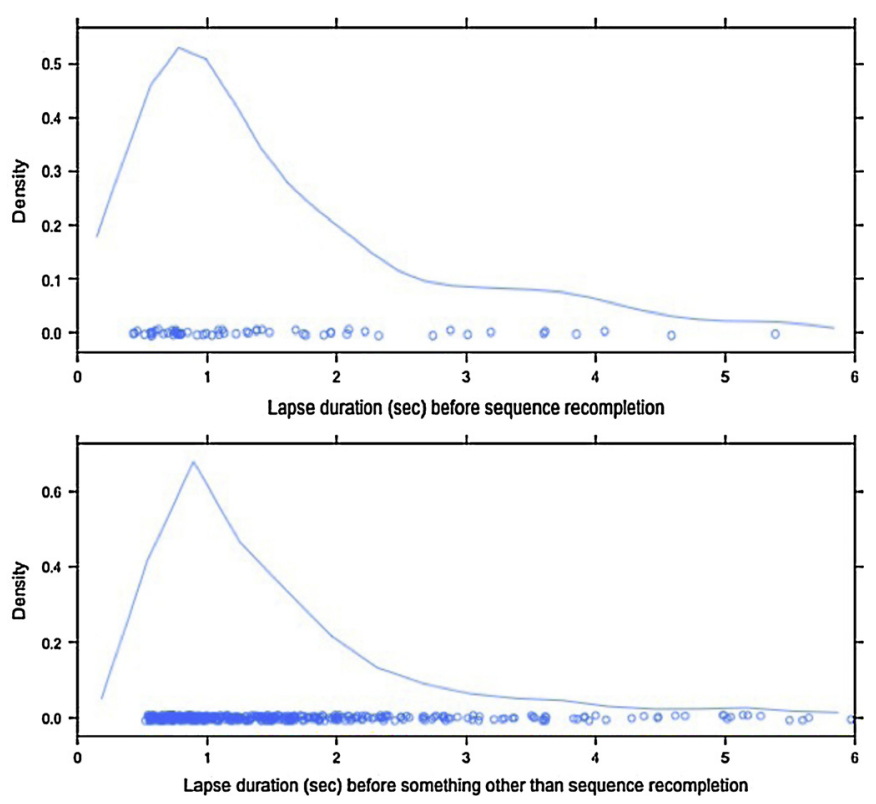

Fig. 1. Timing of sequence recompletion vs. non-sequence recompletion.

practice of sequence recompletion, the specific length of silence (just over a second) appears to be a more general property of lapses in conversation.

\subsection{The sequence recompleting turn}

How does sequence recompletion get done in concrete terms? Regarding verbal/vocal format, participants use various forms for sequence recompletion. These are grouped into types in Table 1. All formats for which there was only one token are listed as "Other".

Unsurprisingly, this inventory shares much in common with what's found in environments of topic-shift (Jefferson, 1981) and sequence closure (Schegloff, 2007). Forms of agreement, acknowledgment, and confirmation comprise the

Table 1

Inventory of sequence recompleters. Frequencies and proportions for types in boldface.

\begin{tabular}{|c|c|c|}
\hline Type and formats & Frequency & Proportion \\
\hline Acknowledgments, agreements, and confirmations & 36 & $43.4 \%$ \\
\hline yeah & 14 & $38.9 \%$ \\
\hline$m m$ & 8 & $22.2 \%$ \\
\hline Other & 8 & $22.2 \%$ \\
\hline$h m$ & 4 & $11.1 \%$ \\
\hline okay & 2 & $5.1 \%$ \\
\hline Assessments & 18 & $21.7 \%$ \\
\hline it's $X\{$ good, weird, awful, funny, annoying\} & 6 & $33.3 \%$ \\
\hline Other & 5 & $27.8 \%$ \\
\hline that's $X\{$ good, cute, great, cool, interesting $\}$ & 4 & $22.2 \%$ \\
\hline oh dear & 3 & $16.7 \%$ \\
\hline Affective vocalizations & 15 & $18.1 \%$ \\
\hline Sighing, deep exhalation & 8 & $53.3 \%$ \\
\hline Laughter & 5 & $33.3 \%$ \\
\hline Other & 2 & $13.3 \%$ \\
\hline Other & 14 & $16.9 \%$ \\
\hline so & 7 & $50 \%$ \\
\hline Idunno & 4 & $28.6 \%$ \\
\hline Other & 3 & $21.4 \%$ \\
\hline Total & 83 & $100.0 \%$ \\
\hline
\end{tabular}


Table 2

Methods for sequence recompletion and types of formats used.

\begin{tabular}{lll}
\hline Method and types & Frequency & Proportion \\
\hline Post-sequence transitions & $\mathbf{3 1}$ & $\mathbf{3 7 . 3} \%$ \\
Affective vocalizations & 9 & $29.0 \%$ \\
Assessments & 8 & $25.8 \%$ \\
Acknowledgments, agreements, confirmations & 7 & $22.6 \%$ \\
Other & 7 & $22.6 \%$ \\
Action redoings & $\mathbf{2 3}$ & $\mathbf{2 7 . 7 \%}$ \\
Acknowledgments, agreements, confirmations & 8 & $34.8 \%$ \\
Assessments & 8 & $34.8 \%$ \\
Affective vocalizations & 6 & $26.1 \%$ \\
Other & 1 & $4.3 \%$ \\
Delayed replies & $\mathbf{1 5}$ & $\mathbf{1 8 . 1} \%$ \\
Acknowledgements, agreements, confirmations & 13 & $\mathbf{8 6 . 7 \%}$ \\
Assessments & 2 & $13.3 \%$ \\
Turn-exiting & $\mathbf{1 4}$ \\
Acknowledements, agreements, confirmations & 8 \\
Other & 6 & $\mathbf{1 6 . 9 \%}$ \\
Total & $\mathbf{8 3}$ & $\mathbf{5 7 . 1 \%}$ \\
\hline
\end{tabular}

largest group of sequence recompleters, followed by various forms of assessment, including constructions like it's $X$ and that's $X$. Also observed are affective vocalizations, which are assessment-like in their conveyance of a speaker's stance. Rounding out the collection are things like standalone so prompts (Raymond, 2004) and Idunno disclaimers.

Other features contribute to the recognizable recompletion of a sequence. Sequence recompleting turns tend to be short (mean duration $=0.64 \mathrm{~s}, n=90$ ), and though spectral measurements weren't taken, they tend to exhibit final intonation. Regarding bodily movement, most sequence recompleting turns involve gaze withdrawal, which is common in sequence-final environments (Rossano, 2012). ${ }^{2}$ And finally, all cases were followed by something other than immediate same-speaker talk. This indicates that they were produced and understood as complete utterances.

The selection of specific compositional features is undoubtedly a sequentially sensitive matter reflecting participants' understandings of just this sequence ending at just this time. However, this paper does not explicitly compare the formats to one another (for an analysis of this sort, see Hoey, 2014). Rather, the cases analyzed in the next section are grouped structurally according to how a given method for sequence recompletion relates to the prior turn, action, or sequence. Four methods are shown: turn-exiting, action redoings, delayed replies, and post-sequence transitions. Turn-exiting and action redoings are systematically available to the same speaker who spoke before the lapse. Delayed replies, by contrast, are available to other participants. And post-sequence transitions are available to any party. Table 2 shows the distribution of these methods and the types of formats employed for them. As the table shows, post-sequence transitions and action redoings are more common than delayed replies and turn-exiting in my collection. And the types of formats used to carry out these actions are varied, although delayed replies and turn-exiting chiefly rely on acknowledgements, agreements, and confirmations.

\section{Methods for sequence recompletion}

The four methods for sequence recompletion are described here, beginning with those methods available to the same speaker (turn-exiting, action redoings), followed by those available to other participants (delayed replies) and to any participant (post-sequence transition). The section ends with a deviant case analysis.

\subsection{Turn-exiting}

Just as participants have methods for extending (e.g., Schegloff, 1996; Couper-Kuhlen and Ono, 2007) or retaining a turn (e.g., Schegloff, 2000; Walker, 2010), so too do they have methods for abandoning or exiting it. Turn-exiting can be done in English with yeah, as shown in Extract 3 in a non-lapse environment. Here, Kelly begins her turn with I remember, then revises it into a question before cutting it off, pausing, then terminating her turn with $(m)$ yeah.

\footnotetext{
${ }^{2}$ Of the $82 / 90$ cases where gaze was detectable, only in two did a speaker gaze to a coparticipant while doing sequence recompletion, and only in seven cases did the recompleter attract coparticipant gaze (see section 5.5 for a deviant case analysis).
} 
(3) RCE28_Lake_27

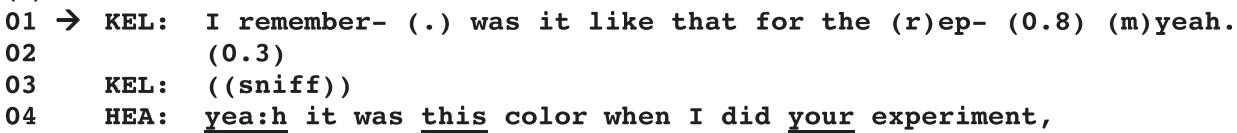

With $(m)$ yeah, Kelly truncates her turn-in-progress and abandons whatever was projected. Turn-exiting is possibly motivated by her having 'realized' an answer to her question while formulating it. Whatever the reason, with $(m)$ yeah she effectively treats the turn she projected as not in need of completion, exits the turn-space, and provides a place for Heather to speak.

Turn-exiting yeah can be used in lapse environments for sequence recompletion. Once a lapse emerges, the same speaker from before the lapse can produce yeah. With this, she can exhibit her prelapse turn as having been complete when it was produced the first time and therefore not in need of modification or completion, as seen below.

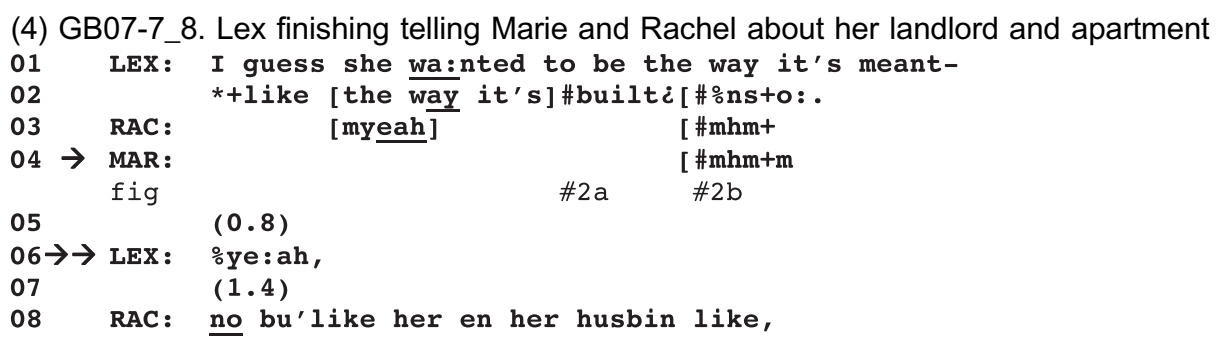

Lex completes her telling and moves toward sequence closure with an upshot of her situation with her landlord (Schegloff, 2007) followed by a turn-final standalone so (Raymond, 2004), and disengagement from talk (Rossano, 2012). Lex's coparticipants acknowledge and ratify Lex's movement to sequence closure by producing weak $\mathrm{mhm}$ tokens (Schegloff, 1982; Jefferson, 1983a; Drummond \& Hopper, 1993; Gardner, 2001) and also disengaging from talk by orienting to their food (Fig. 2). These constitute possible completion of the telling activity, and then a lapse emerges (line 5 ) .

These circumstances provide for the relevance of turn-exiting. The space following possible turn completion is the relevant place to revise, repair, or expand that turn (Schegloff, 1996). Lex orients to her right to speak in this space by selfselecting. However, by producing yeah (line 6), she hearably passes up the chance to modify her turn. She instead uses the post-completion space of her turn to indicate that nothing more is coming from her. She utters yeah with creaky phonation, which is regularly used for sequence closure (Grivičić and Nilep, 2004). The 1.4-s of silence that follows is further evidence that Lex uses yeah to withdraw from the turn-space, rather than revise her turn or project more talk.

Two more cases of turn-exiting after a lapse are shown below. In each case, the same speaker continues after a lapse with yeah to display that no more talk is forthcoming.

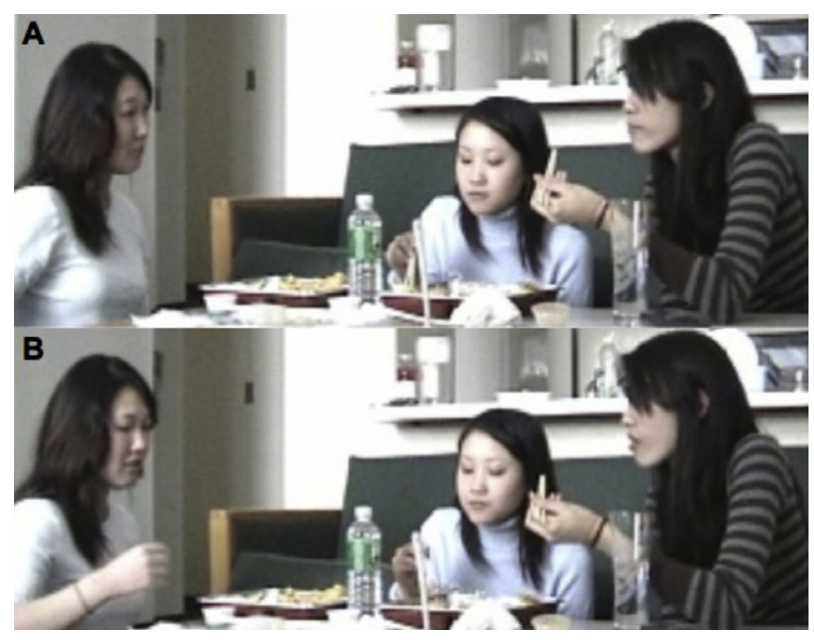

Fig. 2. Lex (left), Marie (middle), Rachel (right). 
(5) RCE25_15. Molly and Hannah talking about drinking habits

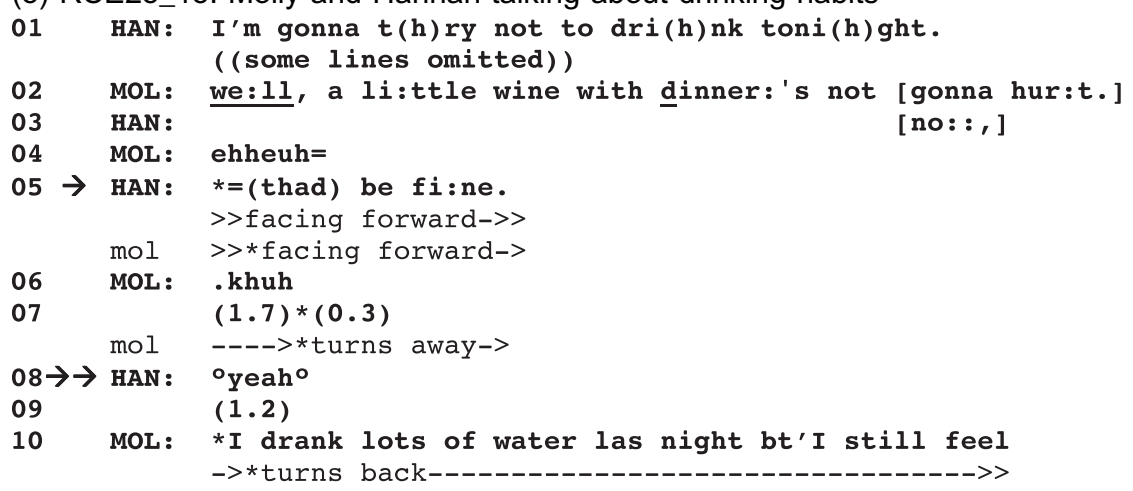

(6) GB07-7_27. Rachel asks Marie when she plans to have children

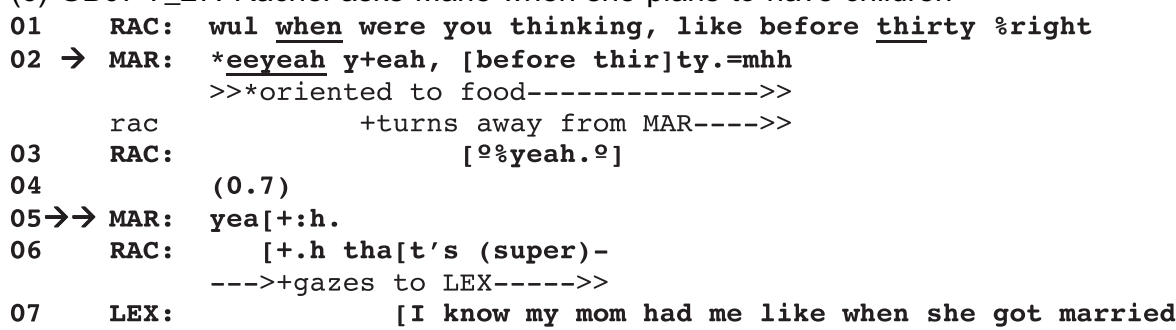

In these cases, Hannah (Extract 5) and Marie (Extract 6) continue speaking after the lapse by producing yeah, with which they exhibit their possibly sequence final turns as being actually sequence final. By rendering the prior sequence as complete again, participants protract the activity of sequence closure, reoccasion the relevance of moving on, and extend the space for others to self-select. With turn-exiting, speakers perform an action that's distinct from whatever they did before the lapse. This contrasts with the action redoings in the next section, where speakers continue speaking after a lapse to redo, in so many words, whatever it was that they did before.

\subsection{Action redoings}

With action redoings, the same speaker continues after a lapse with something not substantially different from what they provided before. The utility of doing observably the 'same thing' as before is that speakers show themselves as passing up the chance to do something different. By demonstrably not modifying a prelapse turn, speakers can both commit to their action as it was produced and display disinterest in developing the topic/sequence further (Jefferson, 1981). Action redoings let speakers situate themselves at the end of a course of action where they are 'still responding'. In this way, they still occupy a sequence-final position where the next turn can be given by another participant. Three variants of action redoings are shown: self-repetition, giving an equivalent version, and unpacking an indexical.

Self-repetition is the most straightforward way to redo an action in a lapse. In Extract $7,{ }^{3}$ Lex tells her coparticipants about a cheap deal on travel. Marie and Rachel register and positively assess it as a "good deal" (lines 2-4), furnishing what could constitute the end of this sequence. A lapse then emerges (line 5).

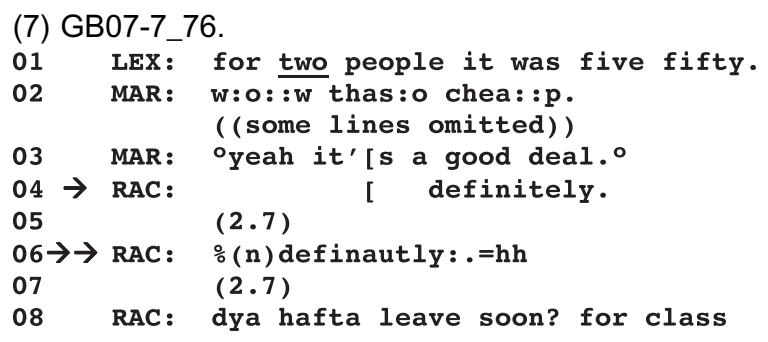

\footnotetext{
${ }^{3}$ This extract is analyzed again in section 5.5 as a deviant case.
} 
After nearly three seconds of silence, Rachel repeats definitely (line 6). With this reproduction, she shows herself as resolute in her assessment of the ticket price, and as having nothing else to say about it. She produces it with altered phonetic shape (prevocalization, creakiness, and final-lengthening), which is one way to implement sequence completion (Grivičić and Nilep, 2004; Curl et al., 2006). And so by indicating that she has nothing more to add, Rachel's self-repetition works to recompletion the sequence.

Rather than repeating the same linguistic content as before, speakers can also provide an equivalent version of that action. In Extract 8, Ann reveals that she thought a rock band under discussion had broken up. Bud corrects her, and adds that in fact they're still active (line 4). Ann receipts the news as unexpected, interesting, remarkable, etc. (line 7). At this point, Bud has the opportunity to expand on the matter (Wilkinson and Kitzinger, 2006; Schegloff, 2007), but instead he merely affirms Ann's reaction (line 8). Bud's decision against saying more on the topic brings the sequence to possible completion, after which a lapse develops (line 9).

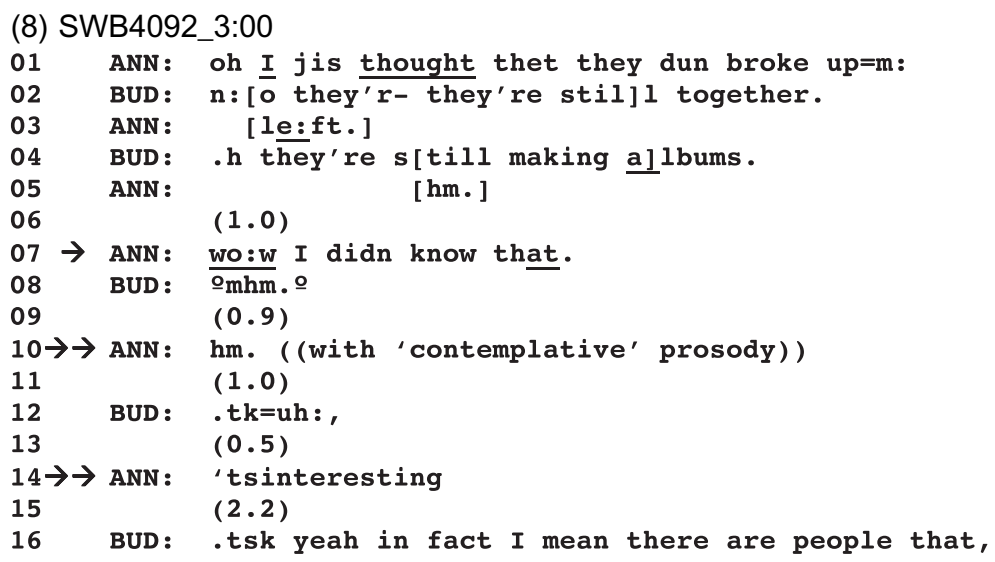

Ann ends the lapse with an equivalent version of her previous reaction by providing another kind of receipt. She produces $\mathrm{hm}$ with falling prosody (line 10), which is hearable in this sequential context as a display of subdued interest. While not as enthusiastically appreciative as her wow in line 7, the stance embodied in this $\mathrm{hm}$ (line 10) is the same kind of sentiment she verbalized in her initial reaction, in that she gives positive uptake of Bud's informing. Ann's action redoing does not engender more talk, though, and so more silence ensues (lines 11-13). Ann ends this second lapse with yet another equivalent version of the same kind of stance from her previous reactions (line 14). With each of these, Ann locates herself as still reacting to Bud's informing, and as not doing any more than that.

Another way that actions get redone is through unpacking an indexical form (see Garfinkel, 1967). Speakers may continue after a lapse to explicate something that was perhaps only indexically or implicitly communicated. Something like an agreement is always indexically tied to its specific occasion of use and may be interpreted in a variety of ways. In Extract 9, Molly's joke about a mutual acquaintance receives laughter and agreement from Hannah in response (lines 13 ). With Molly's laughter particle (line 5), the two participants are officially 'laughing together', which serves to complete this joking sequence (Holt, 2010), after which a lapse develops (lines 4-6).

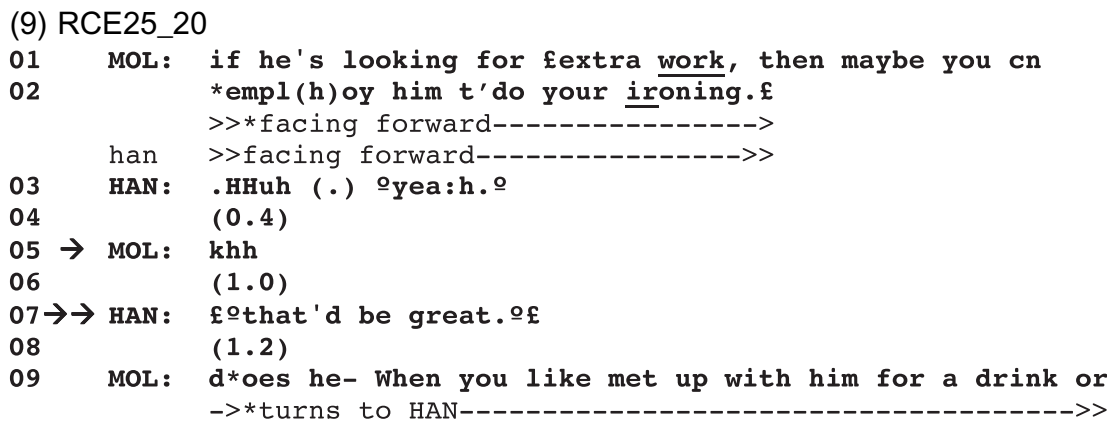

Hannah ends the lapse by unpacking what might have been weakly or tacitly conveyed in her initial agreement. She specifies that'd be great (line 7), which is a stronger and more explicit version of her first reaction in line 3. Because weak agreements may be treated as less-than-full agreement (Pomerantz, 1984), speakers can avoid that possible interpretation by upgrading their agreements. Lapses, that is, might point to a potential insufficiency in the prelapse turn and also provide a place to address it. 
Speakers may thus redo their actions from before the lapse as a way to reinvoke the relevance of moving on and expand the opportunity space for others to self-select. Both turn-exiting and action redoings are systematically available to the same speaker from before the lapse. By continuing after the lapse, they render the silence as a pause, or intra-turn silence. This contrasts with delayed replies, shown in the next section, which transform a lapse into a gap.

\subsection{Delayed replies}

Some forms of sequence expansion-notably sequence-closing thirds-are relevant but not required for the coherence or completion of the sequence that they expand. They are relevant insofar as the prior talk provides for their intelligibility. But at the same time, they are not required in that they were not projected to occur, nor would they be noticeably absent if they weren't produced (Schegloff, 2007; cf. Jefferson and Schenkein, 1978; Kevoe-Feldman and Robinson, 2012; Persson, 2015).

It is this kind of sequence expansion that I have in mind with 'delayed replies'. These replies are relevant and appropriate for their sequential context, but rather than arriving 'on time', they appear after a lapse. Delayed replies are produced in the 'right' place at the 'wrong' time. With them, participants exploit the continued relevance of a reply as a way to end a lapse. In Extract 10, Kelly requests confirmation from Heather about where a mutual friend has lived, and Heather supplies that confirmation (lines 1-2). At this point, Kelly might expand the sequence by, for instance, receipting the answer, targeting it as problematic, asking another question, and so on. Instead, she does nothing, and a 1.1-s lapse emerges (line 3).

(10) RCE28_Lake_28

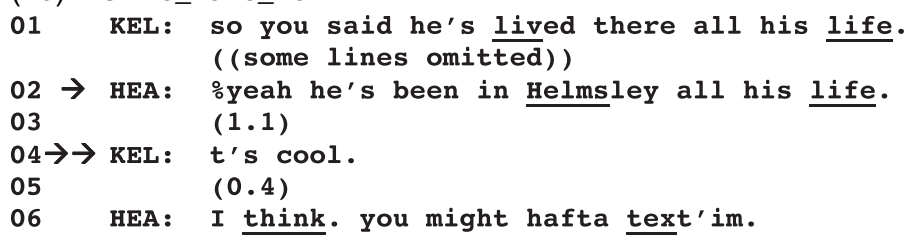

This lapse embodies the participants' orientations to the prior talk as complete. And so when Kelly produces her assessment, $t$ 's cool (line 4), she recompletes what they already treated as complete. Her assessment is analyzably tied to the prior sequence-it is a receipt of Heather's confirmation-yet it is not required for the coherence of that sequence. The participants treated the sequence as adequately complete in line 2. Kelly's' delayed reply points to the continued relevance of a reply in the absence of anything else occurring. By producing a reply after the lapse, Kelly draws out the process of sequence closure and provides an additional opportunity for self-selection by Heather. And indeed, the extract ends with Heather self-selecting to expand the sequence (line 6).

Two more instances of delayed replies appear below. In each case a lapse is followed by some relevant-but-notrequired reply
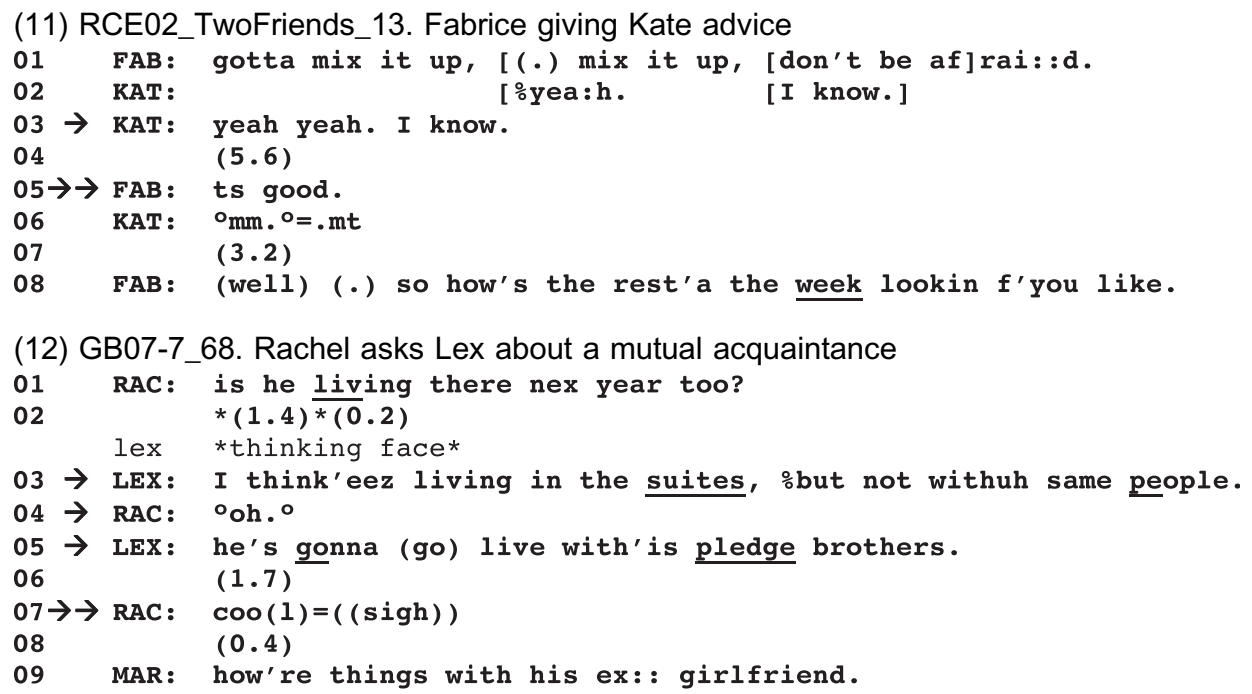

These replies (line 5, Extract 11 and line 7, Extract 12) are analyzably a part of the sequences that they recomplete. Participants use the optionality of such replies as a way to end a lapse. The speakers first treat such replies as 'something 
you don't need to produce', then once the lapse appears, they are treated as 'something you can produce if no one else is speaking'. Speakers may thus produce some sequentially relevant reply after a lapse, essentially placing it in the 'right' place at the 'wrong' time. ${ }^{4}$

The sequence recompletion methods shown so far have been analyzably grounded in the prior turn or sequence. However, participants' talk may be recognizably about the prior sequence, yet not direct outgrowths of it (e.g., Schegloff, 2007: 142). In the next section, I show participants treating prelapse sequences as finished units as a way to recomplete and transition away from them.

\subsection{Post-sequence transitions}

Lapses can weaken the bond of contiguity between one item and the next, decoupling whatever transpired before from whatever comes afterwards. Participants may use this feature of lapses as a resource in transitioning away from the prior sequence and onto something else. With such 'post-sequence transitions', participants simultaneously treat the prior sequence as finished and display preparedness to move on. This often appears as a stance taken up regarding the prior sequence as something that's now finished. In Extract 13, Heather describes to Kelly how disgusting her dad's skin is. Kelly responds by joking about her own dad's appearance (line 4). The two converge in their assessments and laugh together, as Kelly turns away (lines 4-9). This brings their joking activity to possible completion (Holt, 2010), after which a lapse develops.

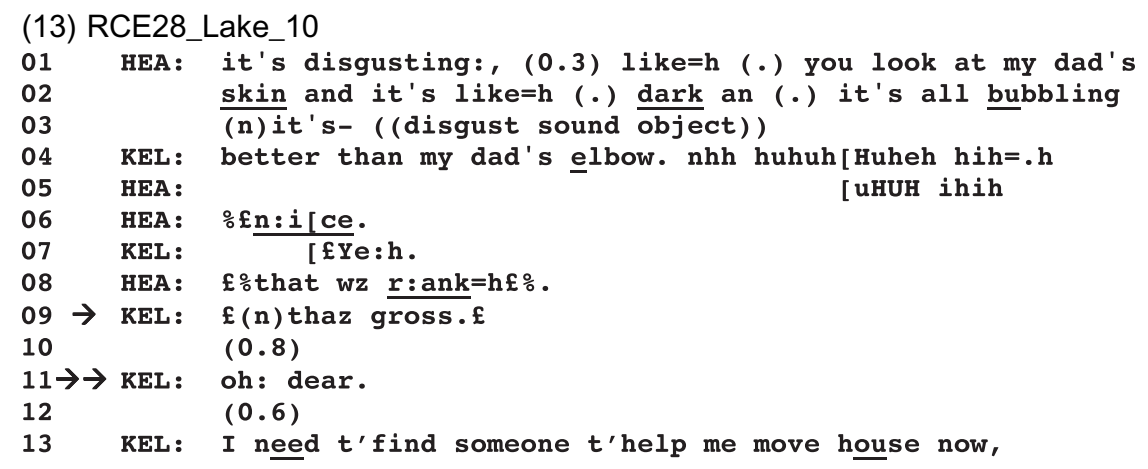

Kelly ends lapse with an 'outloud' utterance (Goffman, 1978) oh dear (line 11). With this, she neither continues with joking, nor starts up something new. Instead, she publicy muses on the matter, treating it as unamenable to change. While her oh dear is not grounded in the prior sequence, it is still recognizably about it. She shows herself as alighting from that playful state, which renders it as complete again and provides for the resumption of serious talk.

The same transitioning work may be done through sighing (see Hoey, 2014). In Extract 14, three friends are talking about the board game they're playing. Maureen comments on how the other team is farther ahead than hers (lines 1-2). Terry responds by exaggeratingly attributing this state of affairs to her teammate Stacy (line 3), who is not present for this exchange. After the participants all appreciate Terry's joke, the sequence concludes and a lapse develops (lines 4-8).

(14) GameNight_24

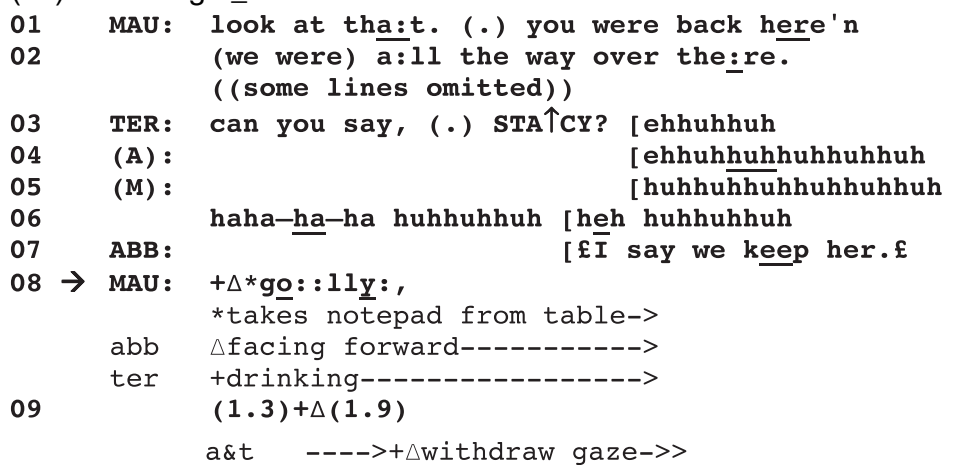

\footnotetext{
${ }^{4}$ Sequence recompletion in Extract (11) is enabled by Kate moving to curtail development of that sequence with her 'multiple sayings' in line 3 (e.g., Stivers, 2004; Golato and Fagyal, 2008; Barth-Weingarten, 2011). I thank an anonymous reviewer for pointing out this connection.
} 
$10 \rightarrow \rightarrow$ ABB: hu: :gh.

11 (1.4)

12 MAU: *what at team, S T, A K, T L,

->gazes to TER------------D>

13

ABB : that's right.

Abby ends the lapse with a sigh (line 10). By producing something that is neither sequence initiation nor a continuation of the joking activity, Abby passes on the opportunity to do either. Instead, with her sigh she disengages from that activity and orients to it as winding down. Her sigh works as an audible transition from a lighthearted state to some next activity.

With post-sequence transitions, participants convey some stance toward whatever transpired in the past sequence as something that's finished or finishing. And so in the same way that speakers can use yeah to exit a turn, they may also use post-sequence transitions to exit an activity or sequence. But in contrast to the other methods shown so far, this device doesn't appear to be restricted to any particular party. Any party in a lapse may thus use things like oh dear and sighing to locate themselves as past the conclusion of a previous course of action, but not yet at the beginning of a next one.

\subsection{A deviant case}

The implementation of a practice does not ensure its success, and its failure can reveal participants' understandings of its normative operation. The analysis put forward in this paper holds that sequence recompletion is designedly not sequence-initial, which means that it is not relevant for recipients to gaze to the speaker who is recompleting the sequence. Of the 82 cases in the collection where gaze was detectable, however, seven deviate from this pattern. This was seen in Extract 7, shown again below as Extract 15. Rachel's self-repeat definitely was analyzed above as a sequence recompleter, but it promptly draws the gaze of Marie (line 4, Fig. 3b).
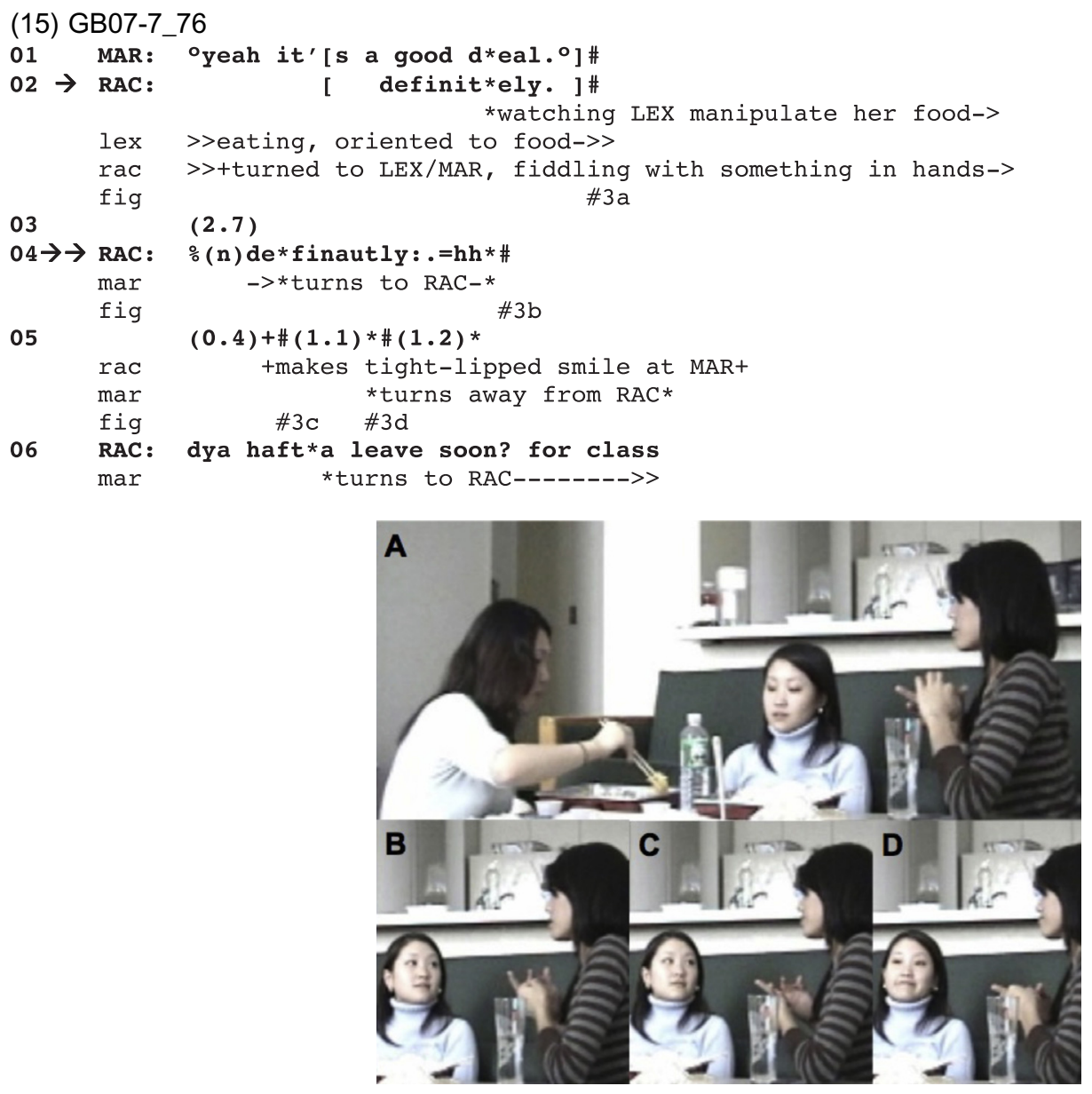

Fig. 3. Deviant gaze behavior by Marie (order: Lex, Marie, Rachel). 
By turning to Rachel at this moment (i.e., while Rachel produces definautly), Marie treats Rachel's self-repeat as potentially sequence-initial. This would appear to contradict this paper's analysis, which holds that sequence recompletion is recognizably sequence-final move. However, other factors can account for its deviance from this norm.

First, vocalizations like \%(n) (line 4) are routinely used as pre-beginning elements when gearing up to talk (Gonzalez Temer and Ogden, 2015), meaning that Marie is justified to some degree in hearing it as potentially sequence-initial. Second, Rachel treats Marie's gaze shift to her as misplaced. Rachel gazes back to Marie, thereby acknowledging that Marie is treating her as 'someone who might speak next', and then produces a tight-lipped smile (line 5, Fig. 3c and d). With this mouth formation, Rachel visibly projects no imminent talk, affirms her stance of 'I will not speak', and retroactively shows her turn in line 4 as having been the end of the sequence. In this way, she shows Marie's analysis of speakership as having been incorrect. And third, Marie understands Rachel's bodily display in this way. After observing Rachel's tightlipped smile, Marie turns away from Rachel (Fig. 3d), visibly abandoning her prior orientation to Rachel as 'someone who might speak next'. This deviant case provides evidence that sequence recompletion is normatively understood as forecasting no further talk.

\section{Discussion}

This paper focused on a particular environment in conversational interaction-lapses-and described a practice for managing the kind of practical problems that lapses can introduce. Lapses can be problematic insofar as they embody the absence of a next speaker and a next-thing-to-do. Confronted with this kind of impasse, participants may recomplete the sequence that they had already treated as adequately complete. Sequence recompletion addresses the issues introduced by the development of a lapse by furnishing someone to speak (the one who self-selects) and something to do (show you won't speak more).

The analysis suggested that sequence recompletion is an alternative to actions like sequence initiation and sequence expansion in lapse environments (Section 4.1), and that the forms used to accomplish sequence recompletion overlap with those linguistic resources used in environments of topic-shift and sequence termination (Section 4.2). Analyses of individual cases showed several methods for sequence recompletion. With turn-exiting (Section 5.1), speakers exhibited their prior turns not as having been merely possibly complete, but as having been actually complete. With action redoings (Section 5.2), speakers produced observably the 'same thing' as before the lapse, which positioned them in the course of action as 'still responding'. With delayed replies (Section 5.3), speakers furnished some relevant-but-not-required reply to conclude a sequence that they had already treated as complete. And with post-sequence transitions (Section 5.4), speakers treated the prelapse sequence as a completed unit and displayed preparedness to take up something else.

With respect to the turn-taking organization, these findings elaborate the ways in which "turns are valued, sought, and avoided" (Sacks et al., 1974: 701, emphasis added). Participants were shown using verbal and vocal resources in lapse environments to display that they would neither expand the prior sequence, nor initiate a next one. Perhaps paradoxically, this yielding of the turn-space to other participants amounts to 'speaking so as to show that you won't speak'. In line with Jefferson's (1981, 1983a) observations on topic-shift and recipiency, the findings reveal participants' tactical usage of acknowledgment tokens, assessments, and other objects for bringing sequences to completion after a lapse, and for displaying disinterest in further topical/sequential development. This article also sheds light on the organization of topicattrition environments (ibid.). Specifically, while Jefferson held that a conversation entered a state of topic-attrition upon two successive passes by speakers, the analyses above show that the same can happen with a single lapse, which represents a collective pass on self-selection.

With respect to sequence organization (Schegloff, 2007), the findings indicate that sequence recompletion is an alternative to things like sequence initiation, sequence expansion, and silence in lapse environments. More precisely, sequence recompletion is somewhere between sequence expansion and silence. It resembles sequence expansion in that what gets added is produced and understood as a minimal addition to or outgrowth of the prior course of action. But at the same time, the choice made in recompleting a sequence is functionally equivalent to remaining silent: either way, a participant indicates that she will not start something new at that moment.

This practice points to the inescapably contingent nature of adequate unit completion (Schegloff, 1982; Ford, 2004). Participants used closure-implicative objects in places where closure was already achieved. This apparent redundancy shows that sequence endings are pliable regions of talk-in-interaction. It shows how arrival at possible sequence completion slackens the adjacency-pair relations that characterized the sequence that is now ready for closure. In sequence organizational terms, sequence recompletion instantiates one way that sequence post-expansion differs fundamentally from pre-expansion or insert-expansion (Schegloff, 2007: 181). In this way, this practice may be conceived of as sequence protraction, where for practical purposes the course of action is extended past its apparent and agreedupon ending. This points to a peculiar aspect of the practice: sequence recompletion regularly results in more silence (and sometimes another recompletion of the sequence), which puts the participants back into the same dilemma as before regarding what should happen next. Even though it doesn't successfully resolve the lapse and restart turn-by-turn talk, 
though, the utility of the practice is that it provides more time to locate something to say, and renews the opportunity for others to say it.

This article shows some ways that participants design their turns to recognizably cohere with what went before a lapse-with the prior turn, action, or sequence. Paramount in this is participants' concern with the local accountability of action (Garfinkel, 1967), part of which means continually displaying to and for others what you will do at that moment and what you won't do. With sequence recompletion, participants manage issues of turn-taking and sequence at the potential ends of courses of action by showing that they will speak at that moment, that they will minimally engage, but that they will do no more than that.

\section{Funding}

This work was funded by a PhD fellowship from the International Max Planck Research School for the Language Sciences.

\section{Acknowledgements}

Previous versions of this paper were presented at the 2016 convention of the National Communication Association in Philadelphia, USA, the 2015 workshop "Revisiting Participation" in Basel, Switzerland, and the 2015 meeting of the American Sociological Association in Chicago, USA. I thank Lorenza Mondada, Kobin Kendrick, Gene Lerner, Will Schuerman, and two anonymous reviewers for their careful readings and helpful critiques of the analysis here.

\section{Appendix A. Table of recordings used}

\begin{tabular}{|c|c|c|c|}
\hline Recording & Description & Number partpts. & Total length \\
\hline Chicken Dinner & Two couples having dinner in apartment & 4 & $32: 14$ \\
\hline Game Night $^{*}$ & Friends chatting, waiting to resume board game & 4 & $22: 31$ \\
\hline GB07-7 & Friends having lunch in apartment & 3 & $38: 40$ \\
\hline HOLT1.1 & Informal phone call between mom and daughter & 2 & $12: 32$ \\
\hline HOLTSO88 & Informal phone call between young couple & 2 & $4: 58$ \\
\hline Housemates ${ }^{\star}$ & Housemates/couple eating and chatting & 3 & $52: 31$ \\
\hline RCE02 Two Friends ${ }^{*}$ & Friends hanging out on campus & 2 & $7: 34$ \\
\hline RCE07 Duck ${ }^{*}$ & Friends hanging out on campus & 3 & $32: 45$ \\
\hline RCE08A UK & Housemates in kitchen preparing for day & 3 & $35: 37$ \\
\hline \multicolumn{4}{|l|}{ Housemates ${ }^{*}$} \\
\hline RCE14 Colleagues* & College instructors creating syllabus & 2 & $25: 53$ \\
\hline RCE15B Swimmers ${ }^{*}$ & Friends having drinks & 3 & $20: 12$ \\
\hline RCE25 Bench* & Friends hanging out on campus & 2 & $30: 23$ \\
\hline RCE28 Lake* & Friends chatting near lake & 2 & $39: 53$ \\
\hline SWB4092 & Telephone chat with predetermined topic & 2 & $5: 00$ \\
\hline
\end{tabular}

* Systematically inspected for the first 50 lapses.

\section{References}

Barth-Weingarten, Dagmar, 2011. Double sayings of German JA-more observations on their phonetic form and alignment function. Res. Lang. Soc. Interact. 44 (2), 157-185.

Button, Graham, Casey, Neil, 1988. Topic initiation: business-at-hand. Res. Lang. Soc. Interact. 22, 61-91.

Couper-Kuhlen, Elizabeth, 1993. English Speech Rhythm. John Benjamins, Amsterdam.

Couper-Kuhlen, Elizabeth, Ono, Tsuyoshi, 2007. 'Incrementing' in conversation: a comparison of practices in English, German, and Japanese. Pragmatics 17 (4), 513-552.

Curl, Traci, Local, John, Walker, Gareth, 2006. Repetition and the prosody-pragmatics interface. J. Pragmat. 38, 1721-1751.

Drew, Paul, Holt, Elisabeth, 1998. Figures of speech: figurative expressions and the management of topic transition in conversation. Lang. Soc. 27, 495-523.

Drummond, Kent, Hopper, Robert, 1993. Acknowledgment tokens in series. Commun. Rep. 6 (1), 47-53.

Ford, Cecilia E., 2004. Contingency and units in interaction. Discourse Stud. 6 (1), 27-52.

Gardner, Ron, 2001. When Listeners Talk. John Benjamins Publishing, Amsterdam.

Garfinkel, Harold, 1967. Studies in Ethnomethodology. Prentice-Hall, Englewood Cliffs, NJ.

Goffman, Erving, 1963. Behavior in Public Places. The Free Press, New York.

Goffman, Erving, 1967. Interaction Ritual. Pantheon Books, New York. 
Goffman, Erving, 1978. Response cries. Language 54 (4), 787-815.

Golato, A., Fagyal, Z., 2008. Comparing single and double sayings of the German response token ja and the role of prosody: a conversation analytic perspective. Res. Lang. Soc. Interact. 41 (3), 241-270.

Goldberg, Jo Ann, 1978. Amplitude shift: A mechanism for the affiliation of utterances in conversational interaction. In: Schenkein, J.M. (Ed.), Studies in the Organization of Conversational Interaction. Academic Press, New York, pp. 199-218.

Gonzalez Temer, Veronica, Ogden, Richard, 2015. A multi-modal analysis of the $\mathrm{mm}$ token in Chilean Spanish interaction. In: Talk presented at the $14^{\text {th }}$ Conference of the International Pragmatics Association, Antwerp, Belgium, 24-27 June 2015.

Goodwin, Charles, 1981. Conversational Organization. Academic Press, New York.

Grivičić, Tamara, Nilep, Chad, 2004. When phonation matters: the use and function of Yeah and creaky voice. Colorado Res. Ling. 17 (1).

Hayashi, Makoto, Yoon, Kyeung-Eun, 2009. Negotiating boundaries in talk. In: Sidnell, J. (Ed.), Conversation Analysis: Comparative Perspectives. Cambridge University Press, Cambridge, pp. 250-278.

Hoey, Elliott M., 2014. Sighing in interaction: somatic, semiotic, and social. Res. Lang. Soc. Interact. 47 (2), $175-200$.

Hoey, Elliott M., 2015. Lapses: how people arrive at, and deal with, discontinuities in talk. Res. Lang. Soc. Interact. 48 (4), $430-453$.

Holt, Elizabeth, 2010. The last laugh: shared laughter and topic termination. J. Pragmat. 42 (6), 1513-1525.

Iwasaki, Shoichi, 1997. The Northridge earthquake conversations: the floor structure and the 'loop' sequence in Japanese conversation. J. Pragmat. 28, 661-693.

Jefferson, Gail, 1981. 'Caveat Speaker': A preliminary exploration of shift implicative recipiency in the articulation of topic. Final Report to the Social Science Research Council (UK).

Jefferson, Gail, 1983a. Notes on a systematic deployment of the acknowledgement tokens 'yeah' and 'mm hm'. Tilburg Papers Lang. Lit. 30, 1-18.

Jefferson, Gail, 1983b. Notes on a possible metric which provides for a 'Standard Maximum' silence of approximately one second in conversation. Tilburg Papers Lang. Lit. 42, 1-83.

Jefferson, Gail, 2004. Glossary of transcripts symbols with an introduction. In: Lerner, G.H. (Ed.), Conversation Analysis: Studies from the first generation. John Benjamins, Amsterdam, pp. 13-34.

Jefferson, Gail, Schenkein, Jim, 1978. Some Sequential Negotiations in Conversation. In: Schenkein, J. (Ed.), Studies in the Organization of Conversational Interaction. Academic Press, New York, pp. 155-172.

Kendrick, Kobin H., 2015. The intersection of turn-taking and repair: the timing of other-initiations of repair in conversation. Front. Psychol. 6, 250.

Kendrick, Kobin H., Torreira, Francisco, 2015. The timing and construction of preference: a quantitative study. Discourse Process. 52 (4), 255289.

Kevoe-Feldman, Heidi, Robinson, Jeffrey D., 2012. Exploring essentially three-turn courses of action. Discourse Stud. 14 (2), $217-241$.

Lerner, Gene H., 2003. Selecting next speaker: the context-sensitive operation of a context-free organization. Lang. Soc. 32 (02), 177-201.

Lerner, Gene H. \& Linton, Larry (2004). Before beginning: Breath taking in conversation (Unpublished manuscript). University of California, Santa Barbara.

Mondada, Lorenza, 2007. Multimodal resources for turn-taking pointing and the emergence of possible next speakers. Discourse Stud. 9 (2), $194-$ 225.

Mondada, Lorenza, 2014. Conventions for Multimodal Transcription. https://franz.unibas.ch/fileadmin/franz/user_upload/redaktion/Mondada_conv_multimodality.pdf (Accessed 20.03.16).

Mondada, Lorenza, 2015. Multimodal completions. In: Deppermann, A., Günther, S. (Eds.), Temporality in Interaction. John Benjamins, Amsterdam, pp. 267-307.

Park, Innhwa, 2010. Marking an impasse: the use of anyway as a sequence-closing device. J. Pragmat. 42, 3283-3299.

Persson, Raymond, 2015. Registering and repair-initiating repeats in French talk-in-interaction. Discourse Stud. 17 (5), $583-608$.

Pomerantz, Anita, 1984. Agreeing and disagreeing with assessments: some features of preferred/dispreferred turn shapes. In: Atkinson, J.M., Heritage, J. (Eds.), Structures of Social Action. Cambridge University Press, Cambridge, pp. 57-101.

R Core Team (2013). R: A language and environment for statistical computing. R Foundation for Statistical Computing, Vienna, Austria. http:// www.R-project.org.

Raymond, Geoffrey, 2004. Prompting action: The stand-alone 'So' in ordinary conversation. Res. Lang. Soc. Interact. 37 (2), $185-218$.

Rossano, Federico, 2012. Gaze behavior in face-to-face interaction. PhD dissertation. Radboud University Nijmegen.

Sacks, Harvey, 1992. Lectures on Conversation. Blackwell, Oxford.

Sacks, Harvey, Schegloff, Emanuel A., Jefferson, Gail, 1974. A simplest systematics for the organization of turn-taking for conversation. Language 50 (4), 696-735.

Schegloff, Emanuel A., 1968. Sequencing in conversational openings. Am. Anthropolog. 70 (6), 1075-1095.

Schegloff, Emanuel A., 1982. Discourse as an interactional achievement: Some use of "uh-huh" and other things that come between sentences. In: Tannen, D. (Ed.), Analyzing Discourse: Text and Talk. Georgetown University Press, Washington, D.C., pp. 71-93.

Schegloff, Emanuel A., 1986. The routine as achievement. Hum. Stud. 9, 111-151.

Schegloff, Emanuel A., 1990. On the Organization of Sequences as a Source of "Coherence" in Talk-in-Interaction. In: Dorval, B. (Ed.), Conversational Organization and its Development. Ablex Publishing, Norwood, NJ, pp. 51-77.

Schegloff, Emanuel A., 1996. Turn organization: one intersection of grammar and interaction. In: Ochs, E., Schegloff, E., Thompson, S.A. (Eds.), Grammar and Interaction. Cambridge University Press, Cambridge, pp. 52-133.

Schegloff, Emanuel A., 1998. Body torque. Soc. Res. 65 (3), 535-596.

Schegloff, Emanuel A., 2000. Overlapping talk and the organization of turn-taking for conversation. Lang. Soc. 29 (01), 1-63.

Schegloff, Emanuel A., 2006. On possibles. Discourse Stud. 8 (1), 141-157.

Schegloff, Emanuel A., 2007. Sequence Organization in Interaction. Cambridge University Press, Cambridge.

Schegloff, Emanuel A., 2009. A practice for (re-) exiting a sequence: and/but/so + uh(m) +silence. In: Fraser, B., Turner, K. (Eds.), Language in Life and a Life in Language. Emerald, Bingley, pp. 365-374.

Schegloff, Emanuel A., Sacks, Harvey, 1973. Opening up closings. Semiotica 8 (4), 289-327.

Sidnell, Jack, Stivers, Tanya (Eds.), 2013. The Handbook of Conversation Analysis. Wiley-Blackwell, Mald. 
Sorjonen, Marja-Leena, 1996. On repeats and responses in Finnish conversations. In: Ochs, E., Schegloff, E., Thompson, S.A. (Eds.), Grammar and Interaction. Cambridge University Press, Cambridge, pp. 277-327.

Sorjonen, Marja-Leena, 2001. Responding in Conversation: A Study of Response Particles in Finnish. John Benjamins, Amsterdam.

Stivers, Tanya, 2004. "No no no" and other types of multiple sayings in social interaction. Hum. Commun. Res. 30 (2), $260-293$.

Tanaka, Hiroko, 2010. Multimodal expressivity of the Japanese response particle Huun: displaying involvement without topical engagement. In: Barth-Weingarten, D., Reber, E., Selting, M. (Eds.), Prosody in Interaction. John Benjamins, Amsterdam, pp. 303-332.

ten Bosch, Louis, Oostdijk, Nelleke, Boves, Lou, 2005. On temporal aspects of turn-taking in conversational dialogues. Speech Commun. 47 (12), 80-86.

Walker, Gareth, 2010. The phonetic constitution of a turn-holding practice. In: Barth-Weingarten, D., Reber, E., Selting, M. (Eds.), Prosody in Interaction. John Benjamins, Amsterdam, pp. 51-72.

Wilkinson, Sue, Kitzinger, Celia, 2006. Surprise as an interactional achievement: reaction tokens in conversation. Soc. Psychol. Quar. 69 (2), 150-182.

Wilson, T., Zimmerman, D., 1986. The structure of silence between turns in two-party conversation. Discourse Process. 9 (4), 375-390.

Elliott Hoey is a PhD student at the Max Planck Institute for Psycholinguistics. His research concerns participants' use of multimodal resources in the constitution of everyday settings. His recent work has explored interactional uses of sighing and drinking. 